\title{
Dynamic Relationship of Commodities Prices and EUR/USD Exchange Rate Trends in the Recent Past
}

\author{
Michele Patanè $^{1}$, Mattia Tedesco $^{1}$, Stefano Zedda ${ }^{2}$ \\ ${ }^{1}$ Department of Business and Law, School of Economics and Management, University of Siena, Siena, Italy \\ ${ }^{2}$ Department of Business and Economics, University of Cagliari, Cagliari, Italy \\ Email: michele.patane@unisi.it, mat_ted@hotmail.it,szedda@unica.it
}

How to cite this paper: Patanè, M., Tedesco, M. and Zedda, S. (2017) Dynamic Relationship of Commodities Prices and EUR/USD Exchange Rate Trends in the Recent Past. Modern Economy, 8, 995-1004. https://doi.org/10.4236/me.2017.88069

Received: July 6, 2017

Accepted: July 31, 2017

Published: August 4, 2017

Copyright @ 2017 by authors and Scientific Research Publishing Inc. This work is licensed under the Creative Commons Attribution International License (CC BY 4.0).

http://creativecommons.org/licenses/by/4.0/ (c) (i) Open Access

\begin{abstract}
Gold and Oil have always had a central role within the international economy, and meet the interests of many investors, and in particular, speculators. The Euro introduction (1999) has added the Euro-Dollar exchange rate as a further main variable that the operators, investing on these commodities, have to consider when implementing their strategies. This paper analyzes the mutual relationship between commodities prices (gold and oil) and the Euro/Dollar exchange rate, within the time frame from 2004 to 2014, so to find which specific variable can give significant information on the expected variation of other variables and on which time horizon. This can support the of investors' choices on taking more effective speculative positions. Results obtained by means of a VAR model show some significant statistical relationship between the three variables on the short term (i.e. when considering daily data), but also some possible relationship on a longer term (monthly data), suggesting that oil prices can give significant information on the expected value of the Euro/Dollar exchange rate.
\end{abstract}

\section{Keywords}

Commodities, Euro/Dollar Exchange Rate, Relationship

\section{Introduction}

Gold and oil prices have always been two reference values for the international economy. Over the years their prices have been highly volatile. Consequently, gold and oil meet the interests of investors, but above all speculators.

From a theoretical point of view, gold price should increase during economic 
crises, and decrease in positive financial context. The opposite is expected for oil prices, as they are mainly linked to the industrial activity, thus positively correlated with the business cycle. The introduction of the euro in 1999 added the euro/dollar exchange rate as a further reference variable, and this induced the operators and speculators on international markets to include this variable in their models and in the implementation of their strategies.

The aim of this paper is to test for the existence of a long or short-term relationship between the prices of gold, oil and the euro/dollar exchange rate, so to give significant information for making profitable investments in commodities, simply observing the dynamics of the euro/dollar exchange or, conversely, taking positions on currencies, considering the price dynamics of the two commodities.

In this aim, the graphical and short-termed analysis can, in some cases, suggest a strong relationship. The graphs in Figure 1, referring to the time span between July 2007 and July 2008, are an interesting example.

Actually, this evidence is misleading, because even if the three series have a similar ongoing only on the considered interval, the relationships are more complex to evaluate.

In fact, during the considered time period, the price of gold increased by 41.22\%; Oil had an $80 \%$ price increase and the Euro/Dollar exchange rate increased by $14.87 \%$.

The prices increase of the three variables is due to the turmoil in financial markets resulting from the subprime mortgage ${ }^{1}$ crisis, that has further weakened the dollar, pulled its value in 2008 to around 1.50 euro.

The Federal Reserve interventions, for limiting the huge deficit of the economy, implemented an expansionary monetary policy for sustaining the exports by means of a weaker currency vs. euro.

The oil price increase was due to two main reasons:

1) The dollar weakness. Demand stayed strong, despite the producing countries in-creased their oil production to compensate the lower profit due to the dollar weakness.

2) The international stock markets crisis. All commodities seemed to be a suitable in-vestment for speculative funds.
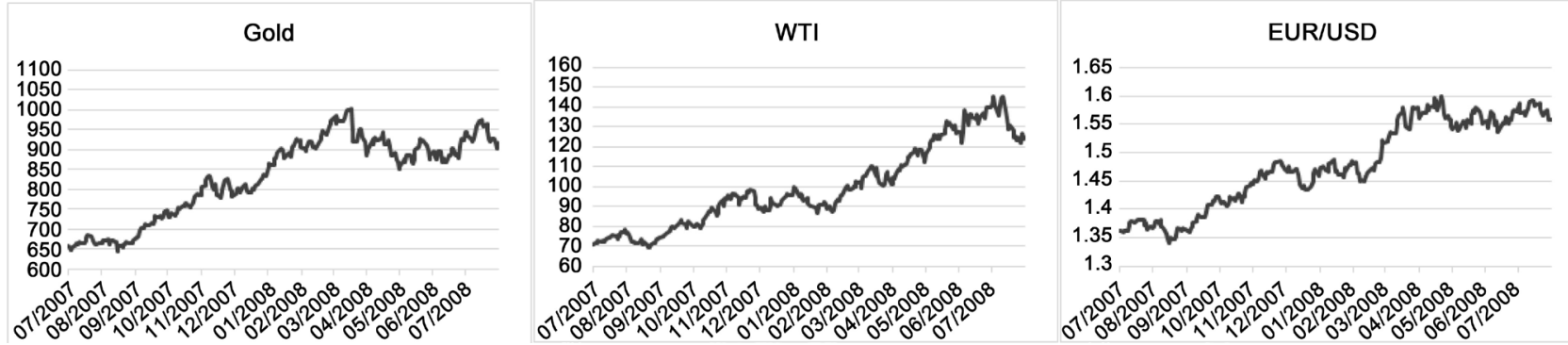

Source: data processing on Bloomberg dataset.

Figure 1. Daily values of gold, oil and Euro/Dollar exchange rate, from July 2007 to July 2008.

${ }^{1}$ A subprime mortgage is a mortgage issued to borrowers with low credit ratings. 
The US dollar weakness led the investors to take "long" positions on gold, pushing up its price. In other words, in this period the demand for gold as a refuge was particularly high. A second sub-period (April 2014-December 2014) (see Figure 2), show a joint decrease of the three variables. Specifically, between April 2014 and December 2014, the gold price fell by $7.59 \%$, oil $41.89 \%$ and the exchange rate decreased by $7.53 \%$.

Specifically, between April 2014 and December 2014, the gold price fell by $7.59 \%$, oil $41.89 \%$ and the exchange rate decreased by $7.53 \%$.

The main elements linked to the decrease of the three goods prices are:

- Regarding gold: gold price conveyed when Fed started the "tapering" of the QE. Moreover, the strong expectation of rising interest rates has recommended maintaining long positions in gold.

- Regarding oil: the oversupply of the Arabian and the US (shale oil) countries, and a weak demand from Asian markets, led to a significant decline in oil prices, which fell from \$102 in July 2014 to \$59 in December 2014.

- Regarding the exchange rate: the ECB started its QE program, that is still ongoing. The resulting lower or even negative interest rates led to a contraction in the euro from $1.35 \$$ in July to $1.23 \$$ in December.

These three short termed observations can suggest a strong correlation between the three variables. But the observation of the same variables on a longer term, clearly contradicts this hypothesis (see Figure 3 ).

It is, thus, fundamental to perform a quantitative analysis, based on appropriate methodologies, for finding the actual linkages between the dynamics of the
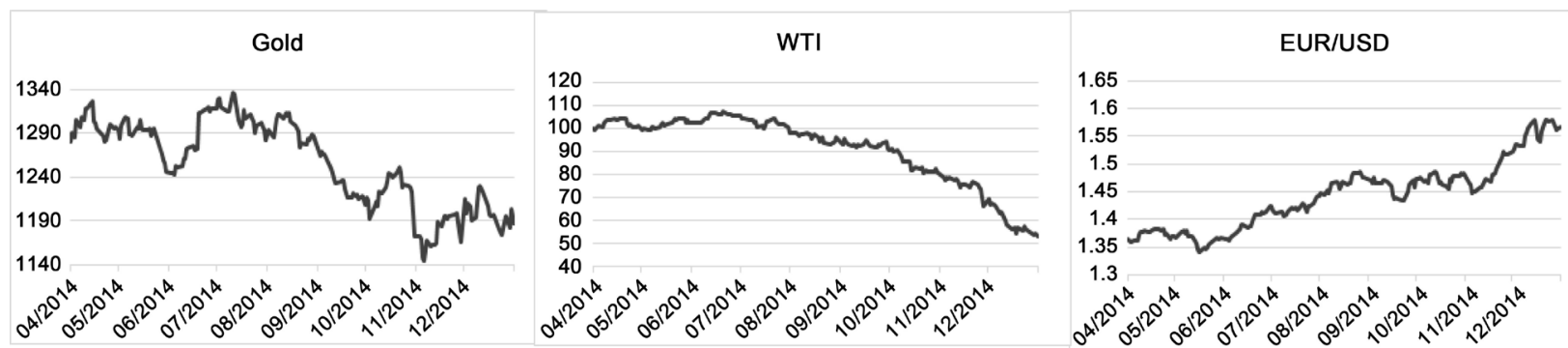

Source: data processing on Bloomberg dataset.

Figure 2. Daily values of gold, oil and Euro/Dollar exchange rate, from April 2014 to December 2014.
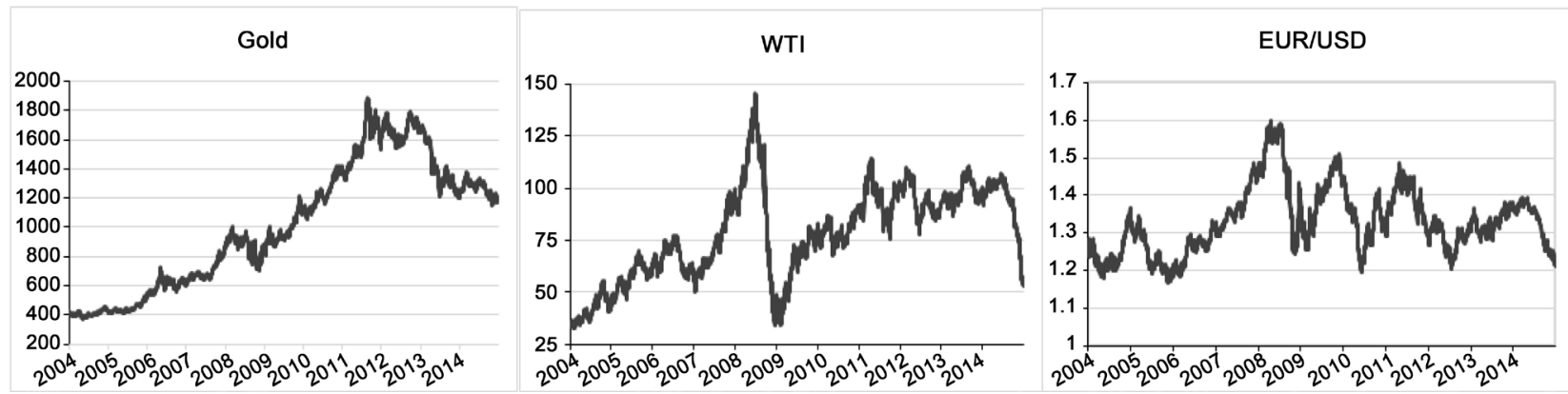

Source: data processing on Bloomberg dataset.

Figure 3. Daily values of gold, oil and Euro/Dollar exchange rate, from January 2004 to December 2014. 
three considered variables.

The analysis here presented is developed by means of a VAR model on data referring to the time span from January 2004 to December 2014.

The reminder of the paper is structured as it follows: section 2 reports the literature review, section 3 and 4 report the econometric model and its results, section 5 discusses the estimation results and its conclusions.

\section{Literature Review}

This paper mainly refers to a literature stream that, through the analysis of prices of gold, oil and exchange rates, investigates over time the relationships between the variations of the considered variables. These studies mainly aim at verifying if the theoretical references on the expected relationships are actually met by market values. These findings always bring useful information for the investors and speculators operating in the foreign exchange market (Forex) and in the commodities market.

Indeed, no one of these studies includes the euro/dollar exchange rate as reference variable.

In the recent literature, the main references are the following:

- [1] analyzed the dynamic relationships between the gold price, the oil price, the exchange rate $^{2}$ and the S \& P 500 index by means of a VAR model (Vector Autoregressive) and the co-integration technique. The results show that the exchange rate is significantly influenced by the price of gold and oil. This evidence suggests that gold and oil play a primary role in determining the exchange rate.

- [2] study, for a period of twenty years, the relationship between the price of gold, oil, exchange rate (US Dollar Index ${ }^{3}$ ) and the price of a basket of stocks measured by the Dow Jones Industrial Average. The results show that not all variables are related to each other. Specifically, the share price and the price of gold appear to be sufficiently related. Conversely, the exchange rate and the oil price are influenced by other factors.

- [3] analyzed the relationship between the value of the dollar and the price of gold and oil (monthly data, time period January 1970-July 2008) using the Granger causality test. The results show a negative relationship between the value of the dollar and the prices of the two commodities. As a result, gold and oil can be considered "safe havens" compared to negative changes in the price of the dollar.

- [4] investigated the relationships between the price of oil and the Canadian/USD exchange rate. The results show that in the long term (using monthly data) there is no stable relationship. In the short term (with daily data) there is instead a strong relationship between the two variables.

- [5] analyzed the relation between some commodities (gold, oil and copper)

${ }^{2}$ The authors used the weighted mean of specific exchange rates relative to US dollar.

${ }^{3}$ The Dollar Index is a measure of the value of the United States dollar relative to other world currencies, where each currency has a specific weight. 
and the exchange rate of their producing countries (Canada, Australia and Chile), in the time period 2000-2009, by means of daily dataset. The results show a link between all variables in the short term; on the other hand these links don't exist for longer period.

- [6] analyzed the dynamic relationship between the price of oil, exchange rate ${ }^{4}$ and the price of shares ${ }^{5}$ through the implementation of a vector autoregression model. The results obtained show that positive shocks in oil prices tend, in the short term, to depress the stock price and the exchange rate, while positive shocks in oil production tend to lower the oil price, and positive shocks on the real economic activity, instead, typically induce the oil price to rise.

These results are not univocal, and this is possibly due to the different modeling, and to the different datasets.

Nevertheless, the main results show significant linkages between the two commodities and the exchange rates on the US dollar on the short term (days), often not confirmed on longer terms (months).

The cited references also show that the euro/dollar exchange rate has not been considered in terms of its linkages to the main commodities. This can be due to the recent (1999) introduction of the European currency in financial markets, and to the small incidence on the European GDP of the gold and oil production, so that no significant theoretical effects of the two commodities prices variations are expected to induce any variations in the exchange rate, thus inducing no interest in testing these effects.

It has, instead, a significant interest for speculators, which are interested in having all the possible information on potential mutual relationship between the main commodities and exchange rates trends, so to implement more effective speculation strategies.

The main aim of this study is to test for possible linkages, on a short (days) and longer (months) term, of gold and oil prices and the euro/dollar exchange rate, and, in case, to have some references on which variable can help in having more precise expectations on the other variables variations.

The analysis is performed on the three variables time series, starting from daily values from January 2004 to December 2014.

\section{Methodology}

The analysis is based on a vector autoregressive model, using data coming from Bloomberg, one of the main financial data providers, which include the daily closing prices of gold (dollars per ounce), oil WTI (dollars per barrel) and the euro/dollar exchange rate, and refer to the time span from January 2004 to December 2014. Overall the dataset is made up of 2870 daily observations for each variable.

The VAR models are based on time series, with multiple dynamic equations in

${ }^{4}$ See Supra note 2 .

${ }^{5}$ The price of shares is measured by means of the MSCI index, which measures 1612 stocks listed in the major developed countries. 
which each variable is considered in its relation to the same and other lagged variables.

It is, thus, possible to summarize the dynamic relationships between the considered variables, with no distinction between endogenous and exogenous (or dependent and independent) variables, but the attention is on current (at time $t$ ) values, as a function of the previous (at time $t-h$ ) values, and the parameters are estimated so to have unbiased and consistent estimations.

As the VAR modeling requests the time series to be stationary, and the Dickey-Fuller test on oil and gold prices, as like on the euro/dollar exchange rate, estimated to be not stationary, the model is applied on the first differences, which resulted to be stationary as requested.

The optimal lag was then chosen on the base of 5 different indexes (LR, FPE, AIC, HQIC, SBIC, see Table 1 and Table 2), and resulted to be 1 for monthly data, and 2 for daily data.

\section{Results}

\subsection{Monthly Data}

As it can be seen on Table 3, the results obtained from monthly data only suggest a weak relationship between the euro/dollar exchange rate and oil prices. More specifically, euro/dollar exchange rate resulted to be significantly (at $10 \%$ level) affected by the previous month oil prices, with a positive sign (positive correlation).

Table 1. Optimal lags selection, gold, oil and euro/dollar exchange rate, monthly values, Jan. 2004-Dec. 2014.

\begin{tabular}{ccccccccc}
\hline Lag & LL & LR & df & p & FPE & AIC & HQIC & SBIC \\
\hline 0 & -658.135 & & & & 85.6099 & 12.9634 & $12.9947^{*}$ & $13.0406^{*}$ \\
1 & -644.538 & $27.194^{*}$ & 9 & 0.001 & $78.2397^{\star}$ & $12.8733^{*}$ & 12.9983 & 13.1821 \\
2 & -641.087 & 6.9021 & 9 & 0.647 & 87.2789 & 12.9821 & 13.2009 & 13.5225 \\
3 & -635.277 & 11.619 & 9 & 0.236 & 93.0292 & 13.0446 & 13.3573 & 13.8167 \\
4 & -631.979 & 6.5957 & 9 & 0.679 & 104.272 & 13.1565 & 13.5629 & 14.1601 \\
\hline
\end{tabular}

Source: data processing on Stata output.

Table 2. Optimal lags selection, gold, oil and euro/dollar exchange rate, daily values, Jan. 2004-Dec. 2014.

\begin{tabular}{ccccccccc}
\hline Lag & LL & LR & df & p & FPE & AIC & HQIC & SBIC \\
\hline 0 & -1108.06 & & & & 0.021805 & 4.68803 & $4.69839^{*}$ & $4.71436^{*}$ \\
1 & -102.69 & 10.735 & 9 & 0.294 & 0.022142 & 4.70335 & 4.74479 & 4.8087 \\
2 & -1089.86 & $25.676^{*}$ & 9 & 0.002 & $0.21787^{\star}$ & $4.68716^{*}$ & 4.75967 & 4.87152 \\
3 & -1082.22 & 15.283 & 9 & 0.083 & 0.021912 & 4.69289 & 4.79647 & 4.95626 \\
4 & -1075.42 & 13.591 & 9 & 0.138 & 0.022117 & 4.7022 & 4.83685 & 5.04457 \\
\hline
\end{tabular}

Source: data processing on Stata output. 
Table 3. VAR estimation on gold, oil and euro/dollar exchange rate, monthly values, Jan. 2004-Dec. 2014.

\begin{tabular}{|c|c|c|c|c|}
\hline$\Delta_{-}$Gold & Coeff. & Std. Err. & Z & $\mathrm{P}>|\mathrm{z}|$ \\
\hline$\Delta \_$Gold t-1 & 0.1162511 & 0.0921111 & 1.26 & 0.207 \\
\hline$\Delta \_$Oil t-1 & 0.2640494 & 0.6922552 & 0.38 & 0.703 \\
\hline$\Delta \_$EUR/USD t-1 & 39.96504 & 146.1948 & 0.27 & 0.785 \\
\hline constant & 4.116153 & 3.998092 & 1.03 & 0.301 \\
\hline$\Delta \_$Oil & Coeff. & Std. Err. & Z & $P>|z|$ \\
\hline$\Delta \_$Gold t-1 & -0.011622 & 0.0127144 & -0.91 & 0.361 \\
\hline$\Delta \_$Oil t-1 & 0.3724225 & 0.0955545 & 3.90 & 0.000 \\
\hline$\Delta \_$EUR/USD t-1 & 26.02258 & 20.1798 & 1.29 & 0.197 \\
\hline constant & -0.0337552 & 0.5518713 & -0.06 & 0.951 \\
\hline$\Delta \_E U R / U S D$ & Coeff. & Std. Err. & Z & $P>|z|$ \\
\hline$\Delta \_$Gold t-1 & -0.0000425 & 0.0000639 & -0.67 & 0.506 \\
\hline$\Delta \_$Oil t-1 & 0.0008917 & 0.00048 & 1.86 & 0.063 \\
\hline$\Delta \_$EUR/USD t-1 & 0.2080736 & 0.1013602 & 2.05 & 0.040 \\
\hline constant & -0.0010629 & 0.002772 & -0.38 & 0.701 \\
\hline
\end{tabular}

Source: data processing on Stata output.

The Granger causality cannot be performed on these values, as the model is only estimated on lag 1 .

\subsection{Daily Data}

As evident from Table $4^{6}$, results show some significant short-term relationship coming from daily data.

The estimations based on daily data show that gold prices are significantly affected by the oil prices with lag 1 and 2 (respectively with positive and negative correlation), and with the euro/dollar exchange rate with lag 1 (negative correlation).

Oil prices are instead linked to gold prices (lag 2) and the exchange rate results to be linked to gold (lag 2) and oil prices (lag 1) with a 5\% significance level.

The Granger causality test, reported on Table 5, confirms the actual linkage between the considered variables. More specifically, it shows that:

- Causality for gold prices as due to oil prices cannot be refused at 5\% significance level;

- Causality for oil prices as induced by gold prices cannot be refused at $1 \%$ significance level;

- Causality for exchange rates as induced by gold and oil prices cannot be refused at, respectively, $10 \%$ and $5 \%$ significance level.

${ }^{6}$ As Table 5 shows, all p-values ("P > $|z|$ ") are lower than 0.05 (0.01) and so we have to reject the null hypothesis with a $5 \%(1 \%)$ significance level. 
Table 4. VAR estimation on gold, oil and euro/dollar exchange rate, daily values, Jan. 2004-Dec. 2014.

\begin{tabular}{|c|c|c|c|c|}
\hline$\Delta \_$Gold & Coeff. & Std. Err. & Z & $\mathrm{P}>|\mathrm{z}|$ \\
\hline$\Delta \_$Gold t-1 & 0.0005361 & 0.0288984 & 0.02 & 0.985 \\
\hline$\Delta \_$Gold t-2 & 0.0353941 & 0.0288035 & 1.23 & 0.219 \\
\hline$\Delta \_$Oil t-1 & 0.3654271 & 0.2264416 & 1.61 & 0.107 \\
\hline$\Delta \_$Oil t-2 & -0.4051922 & 0.2153496 & -1.88 & 0.060 \\
\hline$\Delta \_$EUR/USD t-1 & -87.36052 & 48.3633 & -1.81 & 0.071 \\
\hline$\Delta \_$EUR/USD t-2 & -8.450506 & 47.97282 & -0.18 & 0.860 \\
\hline constant & 0.1703217 & 0.3435947 & 0.50 & 0.620 \\
\hline$\Delta \_$Oil & Coeff. & Std. Err. & Z & $\mathrm{P}>|\mathrm{z}|$ \\
\hline$\Delta \_$Gold t-1 & -0.0003147 & 0.0034184 & -0.09 & 0.927 \\
\hline$\Delta \_$Gold t-2 & 0.0133602 & 0.0034072 & 3.92 & 0.000 \\
\hline$\Delta \_$Oil t-1 & -0.0214938 & 0.0267858 & -0.80 & 0.422 \\
\hline$\Delta \_$Oil t-2 & 0.0263361 & 0.0254738 & -1.03 & 0.301 \\
\hline$\Delta \_E U R / U S D$ t-1 & -1.141769 & 5.720905 & -0.20 & 0.842 \\
\hline$\Delta \_$EUR/USD t-2 & -0.7798057 & 5.674715 & -0.14 & 0.891 \\
\hline constant & 0.0427803 & 0.0406439 & 1.05 & 0.293 \\
\hline$\Delta$ D_EUR/USD & Coeff. & Std. Err. & Z & $\mathrm{P}>|\mathrm{z}|$ \\
\hline$\Delta \_$Gold t-1 & 0.0000201 & 0.0000177 & 1.14 & 0.256 \\
\hline$\Delta \_$Gold t-2 & 0.0000395 & 0.0000177 & 2.23 & 0.026 \\
\hline$\Delta \_$Oil t-1 & 0.000306 & 0.000139 & 2.20 & 0.028 \\
\hline$\Delta \_$Oil t -2 & 0.0000949 & 0.0001322 & 0.72 & 0.473 \\
\hline$\Delta \_E U R / U S D$ t-1 & -0.0106689 & 0.0296957 & -0.36 & 0.719 \\
\hline$\Delta \_E U R / U S D$ t-2 & -0.0247591 & 0.0294559 & -0.84 & 0.401 \\
\hline constant & 0.0001002 & 0.000211 & 0.48 & 0.635 \\
\hline
\end{tabular}

Source: data processing on Stata output.

Table 5. Granger causality test, on gold, oil and euro/dollar exchange rate, daily values, Jan. 2004-Dec. 2014.

\begin{tabular}{ccccc}
\hline Equation & Excluded & ch $\digamma^{2}$ & $d f$ & Prob $>$ ch $^{2}$ \\
\hline$\Delta$ Gold & $\Delta$ Oil & 6.5857 & 2 & 0.037 \\
$\Delta$ Gold & $\Delta$ EUR/USD & 3.3154 & 2 & 0.191 \\
$\Delta$ Gold & ALL & 9.4601 & 4 & 0.051 \\
$\Delta$ Oil & $\Delta$ Gold & 15.394 & 2 & 0.000 \\
$\Delta$ Oil & $\Delta$ EUR/USD & 0.06038 & 2 & 0.970 \\
$\Delta$ Oil & ALL & 16.233 & 4 & 0.003 \\
$\Delta$ EUR/USD & $\Delta$ Oil & 6.2113 & 2 & 0.045 \\
$\Delta$ EUR/USD & $\Delta$ Gold & 5.1681 & 2 & 0.075 \\
$\Delta$ EUR/USD & ALL & 13.292 & 4 & 0.010
\end{tabular}

Source: data processing on Stata output. 
For daily data, as the white noise test on residuals (reported in Table 6) shows p-values higher than 0.05 , it is possible to analyze the effects by means of impulse-response functions.

The following Figure 4, Figure 5, Figure 6 report the impulse-response functions for the considered variables, only showing weak linkages, as the resulting lines seem to be almost flat.

Table 6. White noise test on gold, oil and euro/dollar exchange rate, daily values, Jan. 2004-Dec. 2014

\begin{tabular}{ccc}
\hline Variable & Portmanteau $(Q)$ statistic & Prob. $>$ ch ${ }^{2}(40)$ \\
Gold & 34.5941 & 0.7117 \\
Oil & 53.1062 & 0.0803 \\
EUR/USD & 31.4806 & 0.8300 \\
\hline
\end{tabular}

Source: data processing on Stata output.

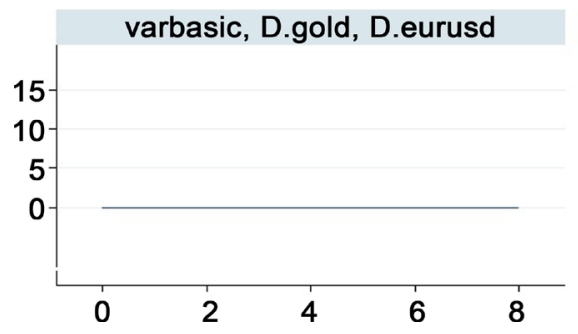

varbasic, D.gold, D.oil

Source: Stata output.

Figure 4. Impulse-response function, gold vs. oil and euro/dollar exchange rate, daily values, Jan. 2004-Dec. 2014.

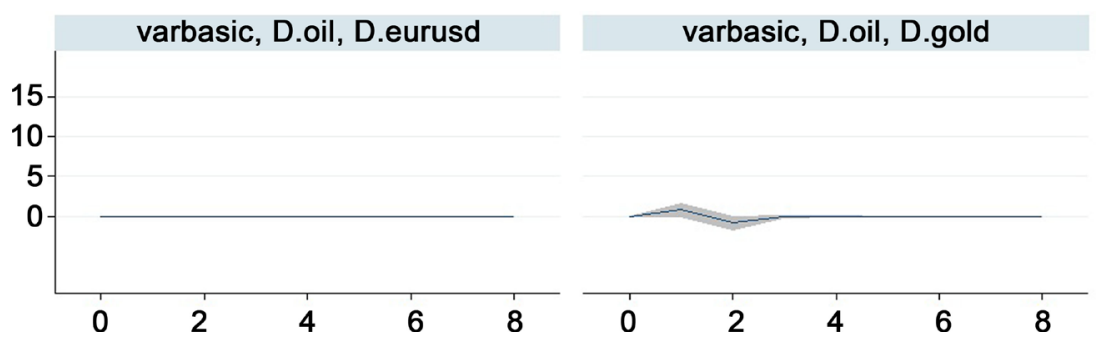

Source: Stata output.

Figure 5. Impulse-response function, oil vs. gold and euro/dollar exchange rate, daily values, Jan. 2004-Dec. 2014.

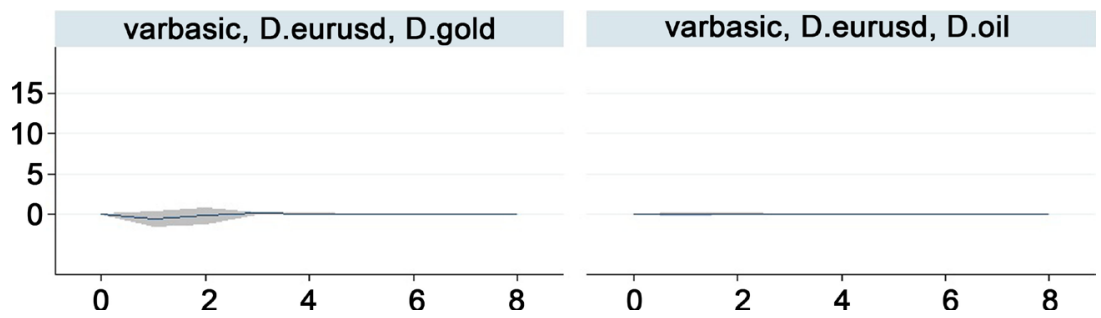

Source: Stata output.

Figure 6. Impulse-response function, euro/dollar exchange rate vs. gold and oil prices, daily values, Jan. 2004-Dec. 2014. 


\section{Conclusions}

The analysis of gold and oil prices and euro/dollar exchange rate performed on daily data from January 2004 to December 2014 shows some significant information.

The VAR estimations, like in [4] and some other studies, report a significant linkage between the two commodities and the euro/dollar exchange rate on the short term, confirmed by the Granger causality test. More specifically, we found a direct linkage among oil and gold prices, and among the euro/dollar exchange rate and gold prices. Regarding the analysis performed on monthly data, we found only a direct link between the oil dynamic and euro/dollar exchange rate. These differences can be due to the short impact of the commodities price shocks, which are typically exhausted in a few days, thus no more significant on longer terms.

The impulse-response functions show that only small variations are expected as a consequence of the price shocks, and that the euro/dollar exchange rate gives no significant in-formation on oil and gold expected trends. As regarding the monthly dataset, the euro/dollar exchange rate does not allow to take a financial position (long or short) on the examined commodities. Instead, the oil prices can give significant information on the expectances of the exchange rate, and suggest possibly effective speculative positions on the currency markets.

Overall, the analysis shows that the linkage between gold price and the exchange rate is significant only in the short term. For this reason investment strategies based on this link, should be implemented for a short time period (few days). These findings bring new information both from the academic perspective, aimed at understanding the actual linkages between the main currencies and commodities, and from the practical perspective of financial speculators, aimed at developing more effective investment strategies, which can have a technical advantage when using the information coming from these findings.

\section{References}

[1] Sujit, K.S. and Rajesh Kumar, B. (2011) Study on Dynamic Relationship among Gold Price, Oil Price, Exchange Rate And Stock Market Returns. International Journal of Applied Business and Economic Research, 9.

[2] Subarna, K.S. and Zadeh Ali, H.M. (2015) Co-Movements of Oil, Gold, the US Dollar and Stocks. Modern Economy, 3, 111-117.

[3] Myeong Hwan, K. and Dilts, D.A. (2011) The Relationship of the Value of the Dollar, and the Prices of Gold and Oil: A Tale of Asset Risk. Economics Bulletin, 31.

[4] Ferraro, D., Rogoff, K. and Rossi, B. (2015) Can Oil Prices Forecast Exchange Rates? Journal of International Money and Finance, 54, 116-141. https://doi.org/10.1016/j.jimonfin.2015.03.001

[5] Zhang, H.J., Dufour, J. and Galbraith, J.W. (2016) Exchange Rates and Commodity Prices: Measuring Causality at Multiple Horizons. Journal of Empirical Finance, 36, 100-120. https://doi.org/10.1016/j.jempfin.2015.10.005

[6] Basher, S.A., Haug, A. and Sadorsky, P. (2011) Oil Prices, Exchange Rates and Emerging Stock Market. Munich Personal RePEc Archive. Paper N³0140. 
Submit or recommend next manuscript to SCIRP and we will provide best service for you:

Accepting pre-submission inquiries through Email, Facebook, LinkedIn, Twitter, etc. A wide selection of journals (inclusive of 9 subjects, more than 200 journals)

Providing 24-hour high-quality service

User-friendly online submission system

Fair and swift peer-review system

Efficient typesetting and proofreading procedure

Display of the result of downloads and visits, as well as the number of cited articles Maximum dissemination of your research work

Submit your manuscript at: http://papersubmission.scirp.org/

Or contact me@scirp.org 